\title{
Roger Chartier entrevistado por Robert Darnton
}

\section{Roger Chartier interviewed by Robert Darnton ${ }^{1}$}

\section{APRESENTAÇÃO}

$\mathrm{O}$

DIÁLOGO ENTRE ROGER Chartier e Robert Darnton aqui publicado ocorreu no Collège de France por ocasião da aula inaugural de uma nova cátedra, denominada Escritas e Culturas na Europa Moderna, tendo Chartier como professor titular.

Em 11 de outubro de 2007, na abertura dessa cátedra, Chartier proferiu a exposição Écouter les morts avec les yeux [Escutar os mortos com os olhos]. O verso do poeta espanhol Quevedo (1580-1645) utilizado como título da aula foi referido por Chartier para evocar pessoas ausentes que contribuíram para que as disciplinas História do livro, História dos textos e História da cultura escrita adquirissem configurações que possibilitaram a existência da cátedra, destacadamente: Henri Jean Martin, Don Mckenzie e Armando Petrucci.

Chartier indica $O$ aparecimento do livro, de Henri Jean Martin e Lucien Febvre, publicado em 1958, como obra fundadora da nova história do livro e destaca que, ao estudar as condições de publicação e circulação dos livros, Martin e Febvre fizeram os estudos sobre história do livro descerem do céu para a terra.

Em relação à obra de Don Mckenzie, falecido em 1999, e sua forma de realizar uma abordagem sociológica dos textos, Chartier destaca que com ele aprendeu a "nunca separar a compreensão histórica dos escritos da descrição morfológica dos objetos que os trazem" (Chartier, 2010: 8). Lembremos que Chartier prefaciou o livro La bibliographie et la sociologie des textes, publicação pela Éditions du Cercle de la Librarie da versão em francês de três palestras proferidas por Don Mckenzie em 1985 na British Library.
1. Transcrição do original e tradução: Dorothée de Bruchard,* apresentação e notas: Sandra Reimão.*** Aulas inaugurais do Collège de France com o título "Écouter les morts avec les yeux" - Professeur Roger Chartier.

* Dorothée de Bruchard é editora e doutoranda na Universidade Federal de Santa Catarina, UFSC. E-mail: dorothee@ escritoriodolivro.com.br.

** Professora Livredocente da Universidade de São Paulo e do Programa de Pós Graduação em Ciências da Comunicação (PPGCOM-USP). E-mail: sandra.reimao@gmail.com. 
De Armando Petrucci, autor, entre outros, de Writers and readers in medieval Italy: Studies in the history of written culture, a lição que Roger Chartier afirma ter retido foi a de "sempre associar, numa mesma análise, os papéis atribuídos ao escrito, as formas e suportes da escrita, e as maneiras de ler" (Idem).

Segundo Roger Chartier, antecessores e contemporâneos como estes e o conjunto de conhecimentos por eles legado e partilhado possibilitam que hoje um pesquisador possa, como ele faz agora, se dedicar a "compreender qual foi o lugar do escrito na produção dos saberes, na troca das emoções e sentimentos, nas relações que os homens mantiveram uns com os outros, consigo mesmos ou com o sagrado" (Idem).

$\mathrm{Na}$ apropriação por Roger Chartier do verso de Quevedo, Escuchar a los muertos con los ojos", ressoam semelhanças com a pergunta de Walter Benjamin em Sobre o conceito de história: "Não existem, nas vozes que escutamos, ecos de vozes que emudeceram?" (Benjamin, 1987: 223).

Instituição única no sistema cultural francês, o Collège de France, fundado em 1530, não fornece diplomas e seus cursos são abertos ao público em geral. O Collège de France tem por divisa Docet omnia, o ensino de todas as coisas, e por missão, voltar-se para os saberes em processo de constituição. A apresentação oficial da instituição afirma:

o Collège de France desfruta de uma situação à parte na pesquisa fundamental e no sistema de ensino superior francês. Não há outro estabelecimento parecido. $\mathrm{O}$ Collège de France não é nem uma universidade, nem uma "grande école". Ele não transmite aos estudantes um saber adquirido a partir de programas definidos. Ele não prepara para nenhum diploma (...) Com efeito, os professores estão engajados a ensinar 'o saber em processo de elaboração' (College, 2011).

Maurice Merleau-Ponty que entre 1952 e 1961 foi professor do Collège na cadeira de Philosophie, em sua aula inaugural denominada Éloge de la Philosophie afirmou "aquilo que o Collège de France, desde sua fundação, se encarrega de dar aos seus ouvintes, não são verdades estabelecidas, é a ideia de uma pesquisa livre" (Merleau Ponty, 1965: 9).

Em um momento de profundas transformações no universo da execução, difusão e preservação do escrito devido à expansão das tecnologias digitais, é mais do que adequado que o Collège de France abrigue essa nova cátedra que se propõe a realizar, assentada "numa história de longa duração da cultura escrita", a abordagem crítica e lúcida de "nossas incertezas e inquietações" atuais sobre o tema, como declarou Roger Chartier ao encerrar sua exposição. (Chartier, 2010: 14). 
No decorrer da aula inaugural, Chartier apresenta com outras palavras esse escopo geral da cátedra: "identificar as durações sedimentadas da cultura escrita para compreender mais acertadamente as mutações que a afetam no presente" (Idem).

Abrindo a conversa, a primeira pergunta que Darnton dirige a Chartier diz respeito ao estatuto dos dados quantitativos no desenvolvimento de suas pesquisas. Essa indagação fornece ocasião para Chartier reforçar que a mensuração é uma base fundamental para o assentamento de uma história cultural e mais especificamente de uma história do livro, mas que é preciso integrá-la com análises das materialidades precisas dos objetos culturais, no caso, livros. Complementando esse raciocínio, Chartier indica que outra vertente de seu trabalho, desenvolvida em conjunto com Daniel Roche, é a história das práticas de leitura. Nesses dois âmbitos - livro e leitura - as pesquisas sobre formas de apreensão e apropriação do escrito deslocaram a ótica de uma abordagem quantitativa simples. Nesse momento, Chartier está se referindo, entre outros, ao clássico artigo Le livre: changement de perspective, escrito em parceria com Roche, incluído na coleção Faire de l'histoire dirigida por Jacques Le Goff e Pierre Nora.

A partir dessa abertura, o diálogo/entrevista desenvolveu temas que podem ser agrupados em dois grandes grupos: 1) questões sobre práticas culturais e 2) observações sobre metodologias para a compreensão analítica dessas práticas.

No primeiro âmbito temático, destaque-se a afirmação, elaborada por Chartier, de que as complexas articulações entre diferenças sociais e práticas culturais em relação a impressos devem ser iluminadas tanto por observações sobre distinções sociais, tal como o faz Pierre Bourdieu, tanto pela análise dos objetos de leitura tal como as elaboradas por Mckenzie.

Enveredando pela temática das metodologias de apreensão de histórias culturais, Chartier destaca o risco de um discurso historiográfico macroscópico substituir uma análise de objetos, que, para serem apreendidos, necessitam de múltiplas referências de vários campos do saber e da cultura.

$\mathrm{Na}$ resposta a respeito de suas aproximações e distâncias em relação a autores clássicos, Chartier declara que Michel Foucault na palestra $O$ que é um autor?, proferida em 1969 no Collège de France como aula inaugural, ao elaborar uma construção teórica conceitual a partir de um problema concreto, no caso, o porquê de haver textos sem autores (como listas telefônicas e contratos) instaurou a questão da autoria textual e da propriedade literária e abriu caminhos de pesquisas múltiplas talvez nunca imaginadas por ele. Chartier declara que seu próprio trabalho se insere em questões desse âmbito e dialoga com esse tipo de procedimento. 
Nos desdobramentos dessas referências, Chartier indica a presença de Durkheim em seus trabalhos especialmente nas questões de representações coletivas nas facetas desenvolvidas por Pierre Bourdieu. Lembremos que em 1988 Roger Chartier realizou uma série de cinco entrevistas com Bourdieu para a rádio France Culture. Essas entrevistas foram publicadas em 1988 pelo INA (Institut National de l'Audiovisuel) e relançadas em 2010 por Agone \& Raisons d'agir sob o título Le sociologue et l'historien.

Na rica conversa entre Roger Chartier e Robert Darnton aparecem ainda dois temas: uma breve referência à questão da globalização e uma observação sobre as novas tecnologias do impresso.

Nesse último tópico, tecnologias do impresso, Chartier salienta que a revolução do livro digital fez ocorrer simultaneamente três mutações que nunca antes haviam se dado em conjunto: mudanças nas formas de registro de um texto, nas técnicas de reprodução e nas práticas de leitura.

$$
* * *
$$

Instigado por perguntas curtas e precisas elaboradas por Robert Darnton, esse diálogo propiciou a Roger Chartier ocasião para explicitar tanto as grandes linhas dos arcabouços e substratos teóricos que sustentam seus trabalhos como também apontar distâncias e divergências pontuais com algumas escolas de pensamentos. Encontros como esses provam que, por mais que os meios eletrônicos atuais possibilitem interações à distância entre pesquisadores, há uma especificidade no diálogo e na discussão acadêmica ao vivo que torna o contato direto e a interação face a face insubstituíveis.

\section{ROGER CHARTIER ENTREVISTADO POR ROBERT DARNTON}

I) Darnton: Eu talvez devesse explicar, Roger, que somos amigos desde muito tempo. Acho que foi em 1973 que nós nos conhecemos. ${ }^{1}$ [Chartier: Exato.] Acompanhei seu trabalho com grande interesse e entusiasmo, reli algumas obras do jovem Roger Chartier, notadamente uma espécie de apologia de uma história quantitativa do livro. Mas você hoje tende a se interessar bastante pelas formas estéticas, e tipográficas, pelas formas que transformam o sentido do escrito. Existe então uma linha evolutiva que vai de uma coisa à outra, ou você de certa forma procura combinar as duas?

1. Depois de lecionar em 1969 e 1970 no Liceu Louis-Le-Grand, em Paris, Chartier tornou-se, em 1970, professor assistente de História Moderna na Universidade Paris I, Panthéon-Sorbonne, onde permaneceu até 1975. A partir de 1975, até 2007, atuou na École des Hautes Études en Sciences Sociales, EHESS, e em 2007 tornou-se titular no Collège de France. Robert Darnton, depois de um breve período, entre 1964 e 1965, como repórter no The New York Times, tornou-se em 1968 professor na Princeton University e aí permaneceu até 2007. Em 1971 Darnton fez a sua primeira estadia como Diretor de Estudos na EHESS. Atualmente é diretor da Biblioteca da Universidade de Harvard; organizador e articulador de programas de acesso livre para acervo de bibliotecas, entre eles o Programa Gutenberg-e; e tem polemizado contra o Google Books Search. 
Chartier: Eu acho que essa evolução é amplamente partilhada, uma vez que não sou o único a tê-la pleiteado, e que segui grandes exemplos nesse sentido... uma forma de reconhecimento, que não deixa de ser uma primeira abordagem absolutamente necessária. Não se pode falar em circulação do livro sem tentar avaliar quem possuía esses livros, quem os lia, qual era a conjuntura do impresso. De modo que, para definir um determinado território de história cultural, o recurso a metodologias que eram antes utilizadas pela história demográfica, pela história econômica, pela história social, foi uma etapa absolutamente fundamental e necessária, e continua sendo, pois do contrário estaríamos arriscados a perder de vista as diferenças sociais em sua relação com a capacidade de escrever, com a propriedade do livro, com os tipos de livros possuídos por tal ou tal meio social. Temos aí, portanto, uma base que é absolutamente fundamental, e que vez ou outra ainda merece ser completada.

Isto posto, acredito que muitos tenham se dado conta de que mensurar a presença do livro não significa necessariamente entrar no conhecimento das práticas de leitura, uma vez que existe uma distribuição extremamente desigual da presença do impresso, a que podem corresponder de forma mais sutil, mais complexa, certo usos do livro, da interpretação dos textos... E a partir do momento em que tentamos - como é inclusive o seu caso - construir uma história de como os textos eram compreendidos, lidos, manejados, nos afastamos quase que necessariamente de uma abordagem quantitativa. Isso porque as fontes não estão aí para nos dar uma resposta imediata, e somos levados a uma abordagem que entrecruze, como foi dito há pouco, com uma análise da modalidade de inscrição dos textos, procurando tirar algumas conclusões no que diz respeito às diferentes formas materiais - ler uma enciclopédia em trinta volumes não é o mesmo que ler um panfleto ou um libelo, um mesmo texto em forma manuscrita ou em forma impressa poderá ter diferentes circulações ou leitores.

De modo que a lição fundamental daquilo que foi uma grande tradição erudita, a da bibliografia, especialmente em sua forma de bibliografia analítica ou material ${ }^{2}$, pode ser absolutamente decisiva para entendermos de que maneira um mesmo texto, dado a ler sob formas diferentes, pode produzir não só diferentes sentidos como diferentes públicos.

2. A caracterização da disciplina Bibliografia Material e sua relação com o estudo dos textos foi assim elaborada por Chartier: "Os postulados que definem a bibliografia e os laços entre suas diferentes modalidades (sistemática, descritiva, analítica, textual) podem ser assim enunciados: $1^{\circ} \mathrm{o}$ estabelecimento de um texto (e, eventualmente, sua edição) supõe a reconstrução rigorosa da história de sua composição e de sua impressão no ateliê tipográfico; $2^{\circ}$ a compreensão desse processo de produção do livro implica a descrição e análise das características físicas dos exemplares conservados da edição (ou edições) do texto em foco. Nesta perspectiva, que é a dos grandes clássicos da bibliografia, a análise material do livro está a serviço do estudo do texto, da confrontação entre suas versões e variantes e, finalmente, do estabelecimento de uma edição que seja a mais exata possível." CHARTIER, Roger. Textes, formes, interprétations. Prefácio a MCKENZIE, D. F. La bibliographie et la sociologie des textes. Paris: Éditions du Cercle de la Librairie, 1991, p. 7. 
E a outra vertente, na qual trabalhamos juntos, também com Daniel Roche ${ }^{3}$, é tentar reconstruir uma história das práticas de leitura a partir das diferentes representações que delas são dadas, a começar pelas representações iconográficas, pictóricas, nas gravuras, mas também a partir das representações de como se deve, ou não se deve ler, em textos de natureza pedagógica ou didática, ou textos que constituem confissões - com a ilusão, porém, que o indivíduo biógrafo de si mesmo às vezes nutre acerca de suas próprias práticas e de seu próprio passado, que existe em todo um conjunto de documentos que pode ser constituído de correspondências, memórias, diários...

De modo que, de novo, essas fontes não se prestam facilmente à análise quantitativa, como se prestariam os inventários de bibliotecas, as percentagens de assinaturas em documentos notariais ou paroquiais. Com isso, acredito que deslocar a questão da presença irregular dos objetos para a questão das apropriações diferenciadas dos textos veiculados por esses objetos - poderíamos dizer o mesmo quanto às imagens -, permitiu que ampliássemos o questionário e, ao mesmo tempo, quase nos obrigou a nos afastarmos de um critério de provas que por muito tempo esteve diretamente ligado à capacidade de mensurar.

II) Darnton: Mas a história social, tal como foi praticada pelos grandes mestres da École des Annales, ainda é central em suas pesquisas e na atual história do livro?

Chartier: Temos aqui vários elementos. $\mathrm{O}$ aspecto da diferença social me parece fundamental, e ele não decorre apenas dessa tradição da história social da Annales, decorre também das referências existentes, inclusive nessa aula inaugural, ao trabalho de Pierre Bourdieu. Ou seja, quer parecer-me que identificar diferentes questões sociais que correspondem a origens, e mais ainda, a trajetórias sociais, é um dado essencial quando se quer ser historiador. Do contrário, cria-se uma total confusão e pode-se acabar generalizando indevidamente o que seria uma prática de um meio social específico. De modo que permanece fundamental este enraizamento de uma história, que chamaremos de cultural, dentro de uma percepção acurada, e tão exata quanto possível, da diferença social.

O que talvez possamos acrescentar é que, por um lado, a diferença social não se mede exclusivamente pela diferença das condições socioprofissionais: pode-se considerar as diferenças entre os sexos como uma diferença social,

3. Daniel Roche escreveu junto com Roger Chartier Le livre: un chagement de perspective, publicado no volume: Le Goff, Jacques et Nora, Pierre. Faire de l'histoire. Nouveaux objets (Paris: Gallimard, pp. 115-136, 1974) e organizou, junto com Robert Darnton, a coletânea The Press in France 1775-1800 (New York: The New York Public Library, 1989). (Edições no Brasil: LE GOFF, Jacques e NORA, Pierre. História. Novos objetos. Rio de Janeiro. Francisco Alves, 1995, 4. ed., tradução de Terezinha Marinho; DARNTON, Robert e ROCHE, Daniel (orgs.). Revolução Impressa. A imprensa na França 1775-1800. São Paulo: Edusp, 1996, tradução de Marcos Maffei Jordan.) 
pode-se considerar que as diferenças entre confissões religiosas são da ordem da diferença social, sempre entrecruzando-as com a diferença socioeconômica mais classicamente medida através das origens, das profissões e dos níveis de fortuna. Foi possível, assim, ampliar a própria definição do que era a diferenciação social. ${ }^{4} \mathrm{E}$ a segunda nuança, ou correção, seria considerar que não se pode estabelecer relações imediatas, mecânicas, entre meios sociais e práticas culturais, uma vez que inúmeras pesquisas mostraram de que maneira indivíduos, homens e mulheres, dos meios populares (no sentido social), podiam se apropriar, para seu próprio sonho, ou desejo, ou necessidade, de textos que nada tinham de popular em si, que pertenciam a uma sociedade inteira.

III) Darnton: No outro sentido, Maria Antonieta lia a Bibliothèque Bleue, ou quase isso...

Chartier: Neste contexto, percebe-se que deve ser repensada o que pode ter sido uma tendência a aproximar demasiadamente a diferença social - quer ao nível macroscópico, popular, letrado, quer a níveis mais sutis de diferenciação socioprofissional - das práticas culturais, uma vez que, talvez desde antes da era moderna, talvez desde a era medieval, há muito mais circulações e apropriações que vêm tornar mais complexa essa articulação entre diferenças sociais e práticas culturais ${ }^{5}$.

Em uma dessas categorias, a das chances, como Pierre Bourdieu procurou pensar, tratava-se não do determinismo absoluto do universo social sobre as produções ou práticas culturais, mas de pensar que existiam espaços de mediação que tinham seus próprios princípios, leis, estruturas. Daí, por exemplo - e é onde está o exemplo neste texto - a ideia de que o que caracteriza os campos culturais, intelectuais ou literários, artísticos, é o fato de neles o passado estar sempre presente. Se hoje lidamos com a economia de Wall Street, as letras de câmbio do século XVI não possuem uma importância absolutamente decisiva.

4. No capítulo Du livre au lire no livro Pratiques de la lecture, Roger Chartier sintetiza essa questão da seguinte forma: "Com efeito, as modalidades de apropriação dos materiais culturais são, sem dúvida, tão ou mais distintivas do que a já desigual distribuição social desses próprios materiais. A constituição de uma escala de diferenciações socioculturais exige, portanto, que paralelamente às sinalizações sobre as frequências de tais ou tais objetos, em tais ou tais meios, sejam encontradas, em suas especificidades, suas práticas de utilização e consumo". Roger Chartier. Du livre au lire In: CHARTIER, R. (direction). Pratiques de la lecture. Paris: Payot, 1993, p. 81. (Há tradução em português, realizada por Cristiane Nascimento, publicada no Brasil pela editora Estação Liberdade em 1996. Esse trecho: p. 78-79.)

5. Sobre o tema, Chartier, em uma abordagem sintética, assim se manifestou: "É preciso recusar toda abordagem que considera que o repertório das literaturas populares exprime a mentalidade ou a visão de mundo dos leitores populares como se costuma supor. Tal relação, comum nos trabalhos sobre a Bibliothèque bleue francesa, os chapbooks ingleses ou les pliegos del cordel castelhanos e catalães, não é mais aceitável. E isso, por várias razões: porque os textos publicados nesses livros e livretos pertencem a gêneros, épocas, de tradições múltiplas e fragmentárias; porque há uma distância considerável (tanto cronológica quanto social) entre o contexto de produção desses textos e suas recepções ao longo dos séculos; porque, sempre uma discrepância separa o que o texto propõe e o que o leitor faz dele". CHARTIER, Roger. Culture écrite et société. L'ordre des livres (XIVe. - XVIIIe. siècles). Paris: Albin Michel, 1996, pp. 217-218 (ver capítulo Lectures populaires). 
Pode haver banqueiros que se interessem por elas enquanto objeto de curiosidade ou coleção... Do mesmo modo, para as ciências mais duras, seu passado é não raro um passado extremamente recente. $O$ passado mais antigo pode ser um objeto de curiosidade, mas não tem pertinência para a prática científica contemporânea. Já nós, e aqui talvez possamos citar Michelet ${ }^{6}$ - o que é quase obrigatório no Collège de France -, podemos citar autores... Não existe um único romancista que não escreva um romance pensando implícita ou explicitamente no Dom Quixote. Há, portanto, uma contemporaneidade desses passados no presente. O que quero dizer é que o fato de dominar este passado pode ser um critério de diferenciação entre os letrados, ou doutos, que conhecem na ponta da língua, ou do pincel, o passado de sua própria prática, e os mais ingênuos, que adentram este espaço da produção ou da prática cultural sem ter esse conhecimento acumulado. Percebia-se, portanto, que uma sociologia dos campos com este aspecto específico da contemporaneidade dos passados no presente podia ser aqui um fator discriminante.

E seria uma ponte possível com uma sociologia dos textos, tal como a pensava Don McKenzie, na medida em que a sociologia dos textos de Don McKenzie se interessa fundamentalmente pelo processo que faz com que um texto seja um texto: ele é composto por alguém, é publicado numa forma ou noutra por toda uma série de intermediários, agentes, e finalmente penetra na escuta, no olhar, ou na leitura daquele que está diante do quadro, do palco, ou do texto impresso. E McKenzie, ao introduzir esta dimensão, veio romper com uma tradição que podia ser puramente descritiva, puramente morfológica, dos objetos impressos, mas que pouco se interessava por seu processo de apropriação ou modo de publicação.

E não vejo aí nenhuma contradição, a partir do momento em que recentrarmos a sociologia de Pierre Bourdieu numa sociologia das produções e das práticas culturais, e em que pensarmos uma análise - que é uma análise muito erudita, muito técnica - dos objetos impressos, dos livros e de seu processo de fabricação, segundo esta perspectiva que McKenzie descrevia como sendo uma perspectiva sociológica, uma vez que envolve atores que se diferenciam um do outro por seu papel, sua competência ou capacidade.

6. Jules Michelet (1798-1874), autor de História da França, precursor no estudo da vida cotidiana para a pesquisa histórica, ocupou no Collège de France a cadeira de Histoire et Morale entre 1838 e 1852. Por suas ideias e manifestações anticlericais (aí incluindo o livro Les Jésuites destinado a mostrar a 'esterilidade' da Companhia de Jesus) suas aulas foram suspensas (em 02/02/1848 e 13/03/1851) e finalmente, em 1852, Michelet foi caçado. Sempre inovando com métodos pouco ortodoxos de se fazer história, Michelet provocou outro escândalo em 1862 ao publicar A Feiticeira, texto no qual, segundo Paul Viallaneix: "a noção corrente de objetividade histórica foi invertida. Que importa se a feiticeira medieval lançou ou recebeu sortilégios, se ela se casou ou não com o Diabo, se ela cometeu uma impostura ou recebeu um dom! Importa que ela acreditava em sua potência mágica e maldita, e que todo um povo acreditou com ela, e precisava acreditar. Tal é o fato histórico da feitiçaria." VIALLANEIX, Paul. Prefácio a MICHELET, Jules. La Sorcière. Paris: Garnier-Flammarion, 1996, p. 21. 
IV) Darnton: Temos, de um lado, uma espécie de determinismo tipográfico e, de outro, uma liberdade magnífica e indeterminada. Existe, portanto, uma tensão entre esses dois polos, essas duas abordagens. Como conciliá-las?

Chartier: Creio que a resposta seria que, entre este absoluto determinismo da forma, de um lado, e, de outro, essa absoluta liberdade do leitor, eu tentaria antes estabelecer um terreno médio, que procuro designar por esta expressão um tanto estranha, de limitação transgredida e liberdade cerceada. As limitações existem, as limitações estão nos textos, nos objetos que veiculam esses textos, nas vozes que enunciam seu sentido. Existem, portanto, diversas limitações que procuram definir um significado. Mas é claro que, quando mais não fosse pelo fato de serem infinitamente repetidas, essas limitações nunca atingem o objetivo, e o leitor nunca está totalmente sujeito a esses sistemas de limitações de que podemos detectar todas as modalidades. Umas eram mais clássicas, ou seja, eram discursos que visavam a um objetivo prático, utilitário, religioso, administrativo; outras eram ligadas à própria forma dos objetos impressos, que permitem tais ou tais usos. De modo que estamos de fato lidando com limitações, mas um erro, talvez, de uma certa abordagem dos textos, tenha sido o de achar que essas limitações eram tão importantes que designá-las significava, ao mesmo tempo, fazer delas a história da leitura. Como se o leitor estivesse dentro deste mecanismo discursivo, ou estivesse dentro desta forma material.

De Certeau, entre outros, restituiu este espaço, que continua existindo, entre essas limitações, que pertencem à ordem do discurso ou à ordem do livro e a apropriação dos leitores. De modo que estamos de fato lidando com limitações possivelmente transgredidas, mas, inversamente - e é aí que acredito que haja um uso infeliz do famoso ensaio sobre a leitura enquanto caça clandestina $a^{7}$ seria um erro acreditar que esta liberdade é absoluta. Na verdade, esta liberdade será sempre cerceada, e seus primeiros limites serão dados pelas competências de leitura.

Daí o fato de que a história da alfabetização (para voltar aqui às suas primeiras observações ${ }^{8}$ ), por mais difícil que seja fazê-la, por mais ambíguo que seja o critério da assinatura enquanto indicadora de alfabetização, não

\footnotetext{
7. "Quer se trate de um jornal ou de Proust, o texto só significa para seus leitores; ele muda com eles; ele se ordena segundo códigos de percepção que lhe escapa. Ele só se torna texto na relação de exterioridade do leitor, em um jogo de implicações e estratégias entre dois tipos de "atenção" combinados: a que organiza um espaço legível (uma littéralité) e a que organiza um andamento necessário à effectuation da obra (uma leitura)". CERTEAU, Michel de. Lire: un braconnage. In: CERTEAU, Michel de. L'invention du quotidien 1. Arts de faire. Paris: Folio, 1990, p. 247. (Há uma tradução em português, realizada por Ephraim Ferreira Alves, publicada no Brasil pela Editora Vozes, 2000, 14 a. ed. , p. 266) 8. Vários trabalhos de Darnton enfocaram índices de alfabetização, capacidades de leitura e circuitos de difusão produzindo alterações em narrativas populares. Entre outros, ver: The great cat massacre and other episodes in French cultural history. Nova York: Basic Books, 1986. (Há uma tradução em português, realizada por Sonia Coutinho, publicada no Brasil pela Editora Graal em 1986.)
} 
deixava de indicar que existem diferentes competências, desde os iletrados analfabetos - que nem por isso serão, pelo menos nas cidades, excluídos da cultura escrita, uma vez que existem possibilidades de transmissão mediante as diversas formas de leitura coletiva - até toda uma gama de competências de leitura, e competências de leitura e escrita. Temos aí, portanto, uma primeira série de determinações, de limitações, que cerceia esta liberdade de apropriação. Mas existe, além disso, todo um conjunto de códigos, de convenções, que determinam em dado momento, numa comunidade de leitores, ou leitoras, as regras que governam sua prática da escrita, e essas convenções, ou códigos interiorizados, incorporados, constituem limites para a interpretação do sentido. Além disso, acho que as convenções estéticas ou sociais que regem o conjunto de um universo social operam igualmente como limitações sobre esta liberdade de apropriação. Quer parecer-me que tudo se dá nesta dialética entre limitação transgredida e liberdade cerceada, o que vale para todos os registros, desde os mais letrados até os mais populares.

V) Darnton: Você acha que o historiador, hoje em dia, também precisa ser um teórico? A teoria entra de forma integral em suas pesquisas?

Chartier: Sim, desde que não se caia naquilo que não deixou de ser uma tentação, um risco, ou seja, substituir a história enquanto análise de situações, quaisquer que sejam elas - podem ser situações sociais, pode ser, na nossa área, a análise de corpus de textos - por um discurso meramente historiográfico ou metodológico.

E acho que existe uma tentação, nesses casos, de a teoria, enquanto exercício filosófico, afastar da prática histórica. Ela tem sua legitimidade, a historiografia é um saber importante, uma teoria da história partilhada por historiadores e filósofos pode ser um objeto importante de discussão. Mas para nós, enquanto historiadores, historiadores dos textos, historiadores das práticas, dos discursos ou das imagens, das situações ou dos comportamentos, o ponto fundamental é encontrar, construir um objeto histórico, se possível um que ainda não tenha sido realmente analisado, ou, se foi, analisá-lo de forma diferente, ou seja, mobilizar recursos, a começar pelas fontes e pelas abordagens que permitam explicá-lo. E é aí, me parece, que numa reflexão com os colegas aparecem elementos passíveis de serem incorporados porque apontam problemas, propõem categorias ou modelos de inteligibilidade, mas não é o caso de desfraldar a teoria. Ora, nesse caso, eu teria certas reservas à ideia da teoria da história, porque a teoria da história se dá não raro a um nível tão macroscópico - tivemos um Toynbee, um Collingwood, grandes modelos, mas que já não correspondem nem um pouco ao que estamos fazendo hoje - que é, em geral, trabalhar com 
corpus que possuem limites, dizem respeito a uma questão, a um problema, uma sociedade, uma prática.

De modo que, com isso - para dar conta de maneira talvez mais acurada, mais criativa ou mais densa, do problema que o historiador construiu - o importante é mobilizar referências que durante muito tempo pareceram alheias ao campo do trabalho histórico.

VI) Darnton: Na sua pesquisa, que não consiste em fazer uma aplicação sistemática de uma teoria, e sim em utilizar uma teoria onde ela for adequada, ainda assim há que fazer escolhas. Quais os teóricos que você não aplicaria?

Chartier: Bem, primeiro, como você disse, existe teoria e teoria. E é uma invenção americana esta de uma teoria francesa, ou french theory, que não existe para os franceses, tendo sido constituída como um mero corpus para exportação, ou apropriação. Tomemos primeiro, para responder a esta pergunta, um exemplo específico. Nos projetos passíveis de serem desenvolvidos no âmbito da pesquisa da cultura escrita, existem várias perguntas possíveis, uma delas oriunda diretamente do título de uma conferência de Foucault: "O que é um autor?", proferida poucas semanas, ou poucos meses, antes de sua eleição para o Collège de France e sua aula inaugural.

O que há neste texto? Pode-se dizer que se trata, neste sentido, de uma construção conceitual ou teórica que parte de uma ideia muito simples: todo texto foi escrito por alguém, mas nem todo texto tem necessariamente um autor. Porque uma lista telefônica, um contrato notariado, ou mesmo uma carta pessoal entre indivíduos, não possuem um autor. A pesquisa de base, portanto, é quando, como, e através de que tipo de texto certos discursos devem necessariamente ser acompanhados por um nome próprio, e outros não. Tratase, portanto, de uma pergunta que se coloca dentro de um âmbito conceitual. Foucault posteriormente esboçou uma cronologia, mas era uma cronologia bastante discutível, já que este não era o problema que mais o interessava: o que mais o interessava era a distinção fundamental que há entre o autor enquanto função do discurso e a realidade fenomenológica ou sociológica, ou seja, o fato de haver pessoas que escrevem textos, e que alguns textos sejam criados numa perspectiva, talvez, estritamente religiosa.

9. Por diversas vezes, Roger Chartier salientou o caráter seminal que a palestra de Michel Foucault Qu'est ce qu'un auteur? teve em seus trabalhos. Lembremos que Michel Foucault foi, entre 1970 e 1984, titular da cátedra Histoire des systèmes de pensée no Collège de France. FOUCAULT, Michel. Qu'est ce qu'un auteur ?, conferência proferida em fevereiro de 1969 na Société française de Philosophie. Publicada no Bulletin de la Société française de philosophie, $\mathrm{n}^{\circ}$ 3, 1969, mais tarde in: Littoral , $\mathrm{n}^{\circ}$ 9, junho de 1983 e finalmente em: FOUCAULT, Michel. Dits et écrits, tomo I, Paris : Gallimard, 1994. Publicado no Brasil com tradução de Inês Autran Dourado Barbosa, in Ditos e Escritos III - Estética: Literatura e Pintura, Música e Cinema. Rio de Janeiro: Forense Universitária, 2001. 
Bem, a partir daí o historiador pode se apropriar desta pergunta, talvez possa também tentar retomar as etapas que Foucault discerniu, notadamente a da criação da propriedade literária, ou a das censuras, que contribuíram fortemente para que se atribuíssem os textos a nomes próprios - no primeiro caso para transformá-lo numa eventual propriedade remuneradora, no segundo para transformá-lo num objeto de condenação e destruição. O historiador pode também, seguindo o seu exemplo e o de McKenzie, rumar para outra dimensão, na qual Foucault sequer havia pensado, que é o fato de que a atribuição de um texto, ou de um corpus de textos, a um nome próprio, também pode se dar pela forma material deste texto: a partir do momento em que vários textos de um mesmo autor são reunidos num mesmo volume, a atribuição ao autor primeiro torna-se quase que uma consequência da materialidade. E isso nos leva para antes da propriedade literária, antes das censuras de Estado ou de Igreja, nos leva para o fim da era do manuscrito, quando alguns autores são, de certa forma, criados pela reunião de várias de suas obras, uma vez que esta reunião confere identidade material a uma composição intelectual.

Percebe-se, portanto, que podemos nos apropriar da pergunta, modificar a cronologia, abrir outros espaços em que se situe a construção do autor, especialmente a partir da materialidade dos objetos. Podemos igualmente tentar fazer, como eu tento, mais duas perguntas. Ou seja, mesmo existindo essa atribuição a um nome próprio, qual a relação entre a escrita a várias mãos, a escrita em colaboração que era, afinal, muito frequente em certos gêneros nos séculos XVI e XVII, e o fato de que, quer nossa própria tradição, quer os livreiros e editores da época as atribuíssem a um único nome. Ou seja: a tensão entre uma prática de escrita que supõe a colaboração e uma lógica editorial que muitas vezes impõe um único nome.

Gostaria, porém, de acrescentar mais uma coisa: a teoria, em outro nível, pode estar presente quando procuramos, hoje, reformular o que alguns podem considerar às vezes como uma tentativa meio sem saída: qual a especificidade do saber histórico na representação do passado? Já que os historiadores não são os únicos que representam o passado. A ficção, desde as peças históricas da época elisabetana até o romance histórico contemporâneo, ou a memória - todas essas memórias proliferantes, institucionais ou individuais - também representam o passado. E acho que por muito tempo os historiadores não se preocuparam muito com essa competição, com essa coexistência que podia haver entre várias diferentes formas de representação do passado.

E se quisermos não negar a força dessas outras representações... - há mais gente lendo romances históricos do que, talvez, nossos próprios livros. A memória possui uma força considerável em todas essas formas encarnadas 
de lugares, monumentos, comemorações, cerimônias etc... - se quisermos, não discutir a legitimidade dessas outras representações do passado, e sim tentar definir o que é próprio da representação histórica do passado, a partir daí nossa disciplina, nossa profissão, entra num outro registro da discussão epistemológica, filosófica, teórica etc., que é: a que condição pode aspirar o trabalho do historiador? Dar uma representação diferente, ou seja, mais adequada, deste passado de que também se apropria o romancista que escreve uma fábula, ou a memória que reconstrói esse passado para seus próprios desejos ou necessidades do presente. E a partir daí, não há como evitar outra discussão, sobre a teoria num sentido bem amplo, uma teoria da história, que se torna uma discussão sobre quais são os critérios que fazem com que este saber possa ser considerado um saber científico (não há motivo para temer esta palavra). E a partir daí, entra-se numa discussão sobre os critérios da prova, sobre a construção do objeto, sobre as regras que, numa comunidade de saber, permitem validar ou não uma análise etc.

VII) Darnton: Compreendo, e eu diria que é esta, inclusive, uma belíssima descrição da sua maneira de trabalhar. Então, quais são os grandes ausentes na sua aula inaugural? Pensando bem, não ouvi o nome de Freud, nem o de Marx, nem o de Durkheim etc.

Chartier: São três casos distintos. Durkheim está ausente, mas não está ausente em outros textos, na medida em que se pensarmos no que dissemos de início, ou seja, na referência a uma sociologia como aquela desenvolvida por Pierre Bourdieu e, evidentemente, se pensarmos numa ideia como, por exemplo, a representação coletiva, é imediata a referência a Durkheim e Mauss, à escola sociológica francesa. E quer parecer-me que eles participam desta perspectiva enquanto pais fundadores de uma história, ou de uma sociologia, em que as representações adquiriram, de saída, a capacidade tanto de serem construídas pelas diferenças sociais como de construí-las, já que as representações mentais também dependem da trajetória ou da origem dos indivíduos no universo social - temos aí o primeiro ensaio de Durkheim sobre as classificações ${ }^{10}$, as classificações mentais como sendo uma incorporação das divisões sociais. Mas, ao mesmo tempo, em sociedades - inclusive esta, mas quero dizer em sociedades menos desenvolvidas do que aquelas que virão depois - essas representações possuem força construtiva porque impõem modelos, delimitam fronteiras, organizam diferenças. Portanto, nessa dinâmica da representação - que foi não

10. Durkheim, Émile; Mauss, Marcel. De quelques formes primitives de classification - contribution à l'étude des représentations collectives. Année sociologique, 6, (1901-1902). Há uma nova edição pela Presses Universitaires de France, Paris, 2002. 
raro banalizada como se se tratasse de reflexos, reflexos mentirosos ou verídicos - ao contrário desta ideia fraca da representação, a ideia forte da representação enquanto incorporação da divisão social e construtiva das diferenças sociais, Durkheim tem seu lugar de pai fundador.

Bem. O caso de Marx é um pouco mais complexo porque acho, por um lado, que o tipo de história que você e eu praticamos se distanciou de uma visão de longuíssima duração de certa sucessão dos universos sociais, dos modos de produção, e que há algo intimidante nesta perspectiva em que existem encadeamentos históricos numa macroescala, como era, por exemplo, a perspectiva da conceitualização... O segundo motivo, além desta timidez perante um monumento deste tipo - e também aí reencontramos Pierre Bourdieu, afinal mais presente em nossa conversa do que na aula inaugural -, é o fato de que toda uma série de conceitualizações, a começar pelas dos campos, visa não somente a se distanciar de um modelo um pouco idealista - como se no universo cultural não houvesse interesses econômicos, implicações financeiras, competições sociais ou simbólicas - mas também a se distanciar de um determinismo rígido que pode ter sido uma forma de herança do marxismo, ou pelo menos de certos marxismos, e nos quais afinal havia como que uma adequação imediata entre uma situação socioeconômica e práticas ou produções culturais. De modo que não estou sugerindo que isso seja necessariamente o que Marx disse ou pensou, pelo contrário, mas houve uma herança, que enrijeceu, reificou de certa forma, essa relação que hoje nos ocupa entre, de um lado, as divisões do universo social concebidas dentro desta perspectiva de história social que você mencionava e, de outro, os objetos que pertencem ao domínio, ou ao campo, da história cultural. Então esta seria uma referência a manejar mais delicadamente, no sentido de evitar esta leitura um pouco previsível, equivocada decerto, mas um pouco previsível do trabalho de Marx e, além disso, esse tipo de conceitualização numa escala de longuíssima duração que se situa um pouco além de nossas ambições e capacidades. Assim que, em relação a Freud, sobre o qual não posso dizer que tenha um conhecimento muito profundo, o problema é o mesmo, o da historicidade.

Isso significa que as teorias pouco presentes, ou ausentes, ou às vezes implicitamente atacadas, são teorias nas quais existe um certo esvaziamento da historicidade, ou seja, teorias nas quais se produzem modelos de compreensão, mas modelos que trazem em si uma vocação à invariância, ao universal, e que não levam em conta a dimensão da pluralidade, da diversidade, da mobilidade histórica.

No caso, já mencionado, da literatura, existem todas essas abordagens que não raro foram identificadas, nos Estados Unidos, com a french theory, nas 
quais o funcionamento linguístico e semântico do discurso é autossuficiente. Isso significa que não existem atores, não existem os produtores dos textos, a recepção, a apropriação não tem importância, existe apenas um funcionamento discursivo decifrado pelo crítico literário. A partir daí, são desconsiderados, portanto, todos os parâmetros históricos que regem a produção, a transmissão e a recepção dos textos tal como definidos pela sociologia dos textos de McKenzie. De novo, não digo que seja necessariamente este o pensamento freudiano, mas ele não raro foi objeto de abordagens de certos críticos que assinalaram esta limitação, ou seja, o fato de se projetar no universal tipos de estruturas da personalidade que na verdade estão historicamente enraizados num momento específico da evolução das sociedades.

Só para concluir este ponto: há um autor que me parece ter indicado como é possível, sem abrir mão de métodos de análise ligados ao estruturalismo e à semiótica, permanecer profundamente historiador. É o nosso saudoso amigo Louis Marin ${ }^{11}$, na medida em que, para ele, a análise dos quadros ou a análise dos textos mobilizavam com uma acuidade, uma sutileza extraordinária, métodos de descrição semiótica e estrutural. Ao mesmo tempo, porém, à diferença de algumas abordagens que desconsideravam a história - um pouco segundo um estrito modelo da antropologia estrutural - para Marin, esses objetos analisados segundo esta grade de compreensão sempre se situavam num contexto histórico extremamente preciso como, por exemplo, o jansenismo de Port-Royal, as teorias da representação do príncipe, a pintura do Quatrocentos... Este é um exemplo que mostra - não podemos levar muito longe essa discussão, o que vai permitir que eu não fique de mal com a república dos estruturalistas - que não existe uma contradição insuperável. Simplesmente, uma das interpretações da tradição francesa marcou de forma fortíssima essa a-historicidade da abordagem estrutural para ir ao encontro dos invariantes de tipo antropológico no sentido primeiro do termo.

VIII) Darnton: Acaso existe hoje em dia uma espécie de globalização da vida intelectual, diferente da república das letras de antigamente? Porque você encarna, de certa forma, o intelectual que está em todo lugar e se refere a várias escolas históricas, filosóficas, literárias, em várias línguas.

Chartier: De fato, como você sabe e pratica, sendo outro exemplo disso, existe uma forma de globalização que se tornou possível graças a vários fatores:

11. Louis Marin participou do projeto que resultou na edição do volume Pratiques de la lecture. Nesse volume há um capítulo seu, Ler um quadro: uma carta de Poussin em 1639. O volume foi dedicado à sua memória. Uma primeira edição do original francês de Pratiques de la lecture foi publicada em 1985 pelas Éditions Rivages e, posteriormente, em 1993, houve uma edição de bolso pela Éditions Payot \& Rivages. 
as colaborações universitárias, a redução do preço das viagens, a comunicação eletrônica, as - com altos e baixos - políticas de tradução etc. Há, portanto, uma série de elementos que não existiam, por exemplo, nos anos 30. A partir daí, vemos que estamos de fato num espaço de circulação mais fácil, mais denso. Mas não seria o caso de nos iludirmos com isso.

Primeiro, até que ponto este espaço de circulação implica a totalidade das comunidades científicas? Isso pode variar de acordo com as ciências, pode variar de acordo com os temas tratados pelos indivíduos, pode variar de acordo com suas possibilidades de acesso a essas condições de viagem, seja ela real ou eletrônica, ou de viagem dos textos... Essa é uma primeira observação que, acredito, deva ser feita acerca dos limites desta globalização.

A segunda observação seria que outra limitação pode advir, me parece, do problema linguístico. Você mesmo comentava ainda há pouco, em uma conversa particular, que muitas línguas estão se perdendo - como, por exemplo, o manejo do francês, ou o conhecimento do francês, inclusive nas universidades americanas que tinham mais tradição neste sentido. Não se trata aqui da questão da francofonia versus o mundo inglês. A questão é que quando se perde esse acesso, a bibliografia fica reduzida, ou seja, a leitura, o conhecimento das tradições, as percepções dos modos de fazer, fica reduzido ao que é produzido num domínio linguístico dado - para citar o caso do inglês - ou traduzido neste domínio linguístico. E porções inteiras da produção intelectual que poderiam ter uma extrema pertinência para pesquisas que não estão ligadas aos objetos dessas obras, mas que poderiam ser inspiradas por seus métodos ou abordagens, desaparecem, deixam de existir, ou passam a existir tão somente em espaços bastante reduzidos da comunicação linguística. E acho que é este um segundo obstáculo, talvez mais perverso, para a globalização. Quero dizer com isso que uma língua globalizada se traduz pelo fato de que porções inteiras do saber acabam desaparecendo. Temos estatísticas mostrando que em muitos colégios americanos já não se aprendem mais línguas estrangeiras, e mesmo que o espanhol tenha crescido em importância, não é bem a mesma coisa. Porque o espanhol remete à realidade latino-americana, remete aos romancistas, mas não remete necessariamente às pesquisas da filologia ou da crítica literária espanhola - que é sem dúvida a mais brilhante no mundo atual, com autores como Francisco Rico, Pedro Cátedra e tantos outros. Em termos de análise do que significa publicar um texto, em termos de análise histórico-filológica das obras dos séculos XVI ou XVII, posso garantir que temos aí modelos ou ensinamentos que poderiam transformar profundamente as práticas desenvolvidas hoje nesta área, na França e também nos Estados Unidos... Mas isso não existe num universo globalizado, só existe dentro do universo de circulação 
de uma língua, e não corresponde, não se agrega a este maior conhecimento do espanhol existente, hoje em dia, nos Estados Unidos. De modo que vejo aí um problema complexo, porque é um problema linguístico, mas não só, um problema que também está ligado a uma certa capacidade de conhecimento, de encontro e, sem dúvida, também está no cerne dos debates sobre a formação.

XIX) Darnton: Estou curioso em saber como você vai situar uma história da leitura eletrônica dentro do conjunto de leituras que você descreve que vão da Antiguidade até a era moderna.

Chartier:Acho que neste caso que estamos discutindo hoje, este problema é duplo. Quero dizer que, de um lado, existem inúmeros discursos - jurídico, econômico, técnico - acerca do universo digital, mas quer me parecer que, com exceção de alguns autores, a começar por você, pouco saber histórico foi convocado para se compreender este universo digital. Talvez só possamos entender suas formas de continuidade mais fortes que as aparências, e principalmente suas formas de inovação, se o relacionarmos com uma história de maior duração da cultura escrita e, em especial, no exemplo que você dava, das práticas de leitura.

Com efeito, a prática de leitura frente à tela, descontínua, segmentada, assume um sentido bem diverso se a comparamos com a mesma descontinuidade tornada possível por um livro em sua forma impressa clássica. Como você bem lembrava ${ }^{12}$, ninguém é obrigado a ler todas as páginas de um livro impresso, pode-se folhear este livro, fazer a leitura de um fragmento, uma leitura descontinuada, mas há uma grande diferença: no caso do livro impresso esta descontinuidade ou este fragmento são relacionados a uma totalidade que é imediatamente tornada perceptível pelo objeto, ao passo que no universo digital este fragmento pode ser absolutamente apartado de qualquer compreensão da totalidade de que é extraído, se é que essa expressão faz sentido. De modo que vemos a relação entre fragmento e totalidade ser completamente alterada pela passagem do códex para a tela. Este é um exemplo.

Outro exemplo seria mostrar que, pela primeira vez, nesta mutação do presente, três tipos de mutações que sempre estiveram separadas são agora contemporâneos: mutações das práticas de leitura, mutações das formas de inscrição do texto e mutações na técnica de comunicação ou reprodução do escrito. Evidentemente, podemos acrescentar que esta técnica permite não só a

12. Ver: DARNTON, Robert. The case of books. Past, present and future. New York: Public Affairs, 2009. A edição em francês, com tradução de Jean-François Sené, denomina-se Apologie du livre. Demain, aujourd'hui, hier. Paris: Gallimard, 2011. O título da edição brasileira, com tradução de Daniel Pellizzari, se aproxima da denominação da edição norte-americana: A questão dos livros. Passado, presente e futuro. São Paulo: Editora Companhia das Letras, 2010. Sobre o tema em foco ver especialmente o capítulo Os mistérios da leitura. 
transmissão do escrito como a articulação com a palavra viva, o som, a imagem, inclusive móvel.

Assim, é possível avaliar a contemporaneidade dessas três mutações - técnica, morfológica e cultural - se as referirmos, por exemplo, ao momento em que Gutenberg inventa uma técnica nova, mas o livro continua sendo o mesmo - um códex manuscrito ou um códex impresso possui as mesmas estruturas fundamentais. Podemos pensar que a invenção do códex, no primeiro século da era cristã, constitui uma transformação considerável, já que com isso se tornam possíveis práticas impossíveis com os antigos rolos: escrever enquanto se lê, folhear as páginas, indexar um livro. Ao mesmo tempo, porém, a técnica permanece a mesma, ainda se trata de livros copiados a mão. E as revoluções da leitura que foram estudadas e, às vezes, discutidas, situam-se sempre dentro de uma certa estabilidade, tanto técnica como morfológica.

Ora, estamos hoje diante de uma contemporaneidade. A única nuança, ou limite, é que esta mutação, tanto técnica como morfológica e cultural, situa-se num mundo em que continuam presentes as técnicas anteriores de reprodução dos textos. Ainda escrevemos a mão, ainda lemos vários tipos de objetos impressos. De modo que todo o problema do diagnóstico está no equilíbrio, na competição, na concorrência, na coexistência entre essas três formas principais - existem outras, mas essas são as principais - de inscrição dos textos. Quero dizer com isso que, ao que me parece, uma perspectiva histórica de longa duração pode nos levar a oferecer diagnósticos um pouco diferentes desses que são dados mais tradicionalmente, de forma mais apressada, sobre este universo. $\mathbf{M}$

\section{REFERENNCIAS}

BENJAMIN, Walter. Über den Begriff der Geschichte. In: Gesammelte Schiften I-2. Frankfurt am Main: Suhrkamp, 1980, pp. 691-704. (Há uma tradução em português, realizada por Sergio Paulo Rouanet, publicada no volume Magia e técnica, arte e política. Ensaios sobre literatura e cultura. Coleção Obras Escolhidas, vol. 1. São Paulo: Editora Brasiliense, 1987, p. 222-232.)

BOURDIEU, Pierre e CHARTIER, Roger. Le sociologue et l'historien. Marseille; Paris: Agone \& Raisons d’agir, 2010. (Trad. O sociólogo e o historiador, por Teixeira, Guilherme João de Freitas. São Paulo: Autêntica, 2011.)

CHARTIER, Roger. Écouter les morts avec les yeux. Paris: Collège de France, Fayard, 2008. (Há uma tradução em português, realizada por Jean Briant, publicada na Revista Estudos Avançados do Instituto de Estudos Avançados da Universidade de São Paulo, vol. 24, n.69, 2010, pp. 6-30.) 
; ROCHE, Daniel. Le livre: un chagement de perspective. In: LE GOFF, Jacques et NORA, Pierre. Faire de l'histoire. Nouveaux objets. Paris: Gallimard, pp.115-136, 1974. (Publicado no Brasil com tradução de Terezinha Marinho e revisão técnica de Gadiel Perruci, pela Editora Francisco Alves, em 1976, p.99-113.)

FEBVRE, Lucien et MARTIN, Henri-Jean. L'Apparition du livre. Paris: Albin Michel, 1971. FOUCAULT, Michel. Qu'est-ce qu'un auteur?. In: Dits et écrits. Paris: Gallimard, vol. I, pp. 789-821, 1994. (Publicado no Brasil com tradução de Inês Autran Dourado Barbosa. In: Ditos e Escritos III - Estética: Literatura e Pintura, Música e Cinema. Rio de Janeiro: Forense Universitária, 2001, p.264-298.)

MCKENZIE, D. F. Mckenzie, D. F. La bibliographie et la sociologie des textes. Paris: Éditions du Cercle de la Librairie, 1991 (edição original: Bibliography and Sociology of Texts. The Panizzi Lectures 1985. Londres: The British Library, 1986).

MERLEAU-PONTY. Éloge de la philosophie et autres essays. Paris: Gallimard, 1965.

PETRUCCI, Armando. Writers and readers in medieval Italy: Studies in the history of written culture. New Haven; Londres: Yale University Press, 1995.

\section{Endereços eletrônicos}

CHARTIER, Roger. "Escutar os mortos com os olhos". Estud. av. [online]. 2010, vol.24, n.69, pp. 6-30. ISSN 0103-4014.

COLLEGE de France. Le Collège. Disponível em:

$<$ http://www.college-de-france.fr/default/EN/all/ins_pre/index.htm>. 